\title{
Physical Activity, Bone Health, and Obesity in Peri-/Pre- and Postmenopausal Women: Results from the EPIC-Potsdam Study
}

\author{
Juliane Menzel ${ }^{1} \cdot$ Romina di Giuseppe $^{1} \cdot$ Angelika Wientzek $^{2} \cdot$ Anja Kroke $^{3}$. \\ Heiner Boeing ${ }^{2} \cdot$ Cornelia Weikert $^{1,4}$
}

Received: 18 March 2015/Accepted: 17 June 2015/Published online: 25 June 2015

(c) The Author(s) 2015. This article is published with open access at Springerlink.com

\begin{abstract}
Physical activity (PA) is suggested to increase the peak bone mass and to minimize age-related bone loss, and thereby to reduce the risk of osteoporosis. However, the relation between PA and bone health considering the obesity status is unclear so far. The present study examines the association between PA levels and calcaneal broadband ultrasound attenuation (BUA), particularly under consideration of obesity. Data from a population-based sample of 6776 German women from the EPIC-Potsdam cohort were analyzed. Calibrated PA data were used. Statistical analyses were stratified by menopausal and obesity status. Multiple linear regression was used to model the relationship between PA and BUA levels after adjustment for age, body mass index (BMI), smoking status, education, alcohol and calcium intake, and hormone use. Peri-/premenopausal had higher BUA levels $(112.39 \pm 10.05 \mathrm{~dB} / \mathrm{MHz})$ compared to postmenopausal women $(106.44 \pm 9.95 \mathrm{~dB} /$ $\mathrm{MHz}$ ). In both groups, BUA levels were higher in the
\end{abstract}

Electronic supplementary material The online version of this article (doi:10.1007/s00223-015-0027-0) contains supplementary material, which is available to authorized users.

Juliane Menzel

Juliane.Menzel@dife.de

1 Research Group Cardiovascular Epidemiology, German Institute of Human Nutrition Potsdam-Rehbruecke, Nuthetal, Germany

2 Department of Epidemiology, German Institute of Human Nutrition Potsdam-Rehbruecke, Nuthetal, Germany

3 Department of Nutritional, Food and Consumer Sciences, Fulda University of Applied Sciences, Fulda, Germany

4 Institute for Social Medicine, Epidemiology and Health Economics, Charité University Medical Center, Berlin, Germany fourth compared to the lowest quartile of PA ( $p$ for trend $<0.05$ ). In women with $\mathrm{BMI}<30$, but not BMI $\geq 30 \mathrm{~kg} / \mathrm{m}^{2}$, PA remained positively associated with BUA levels ( $p$ for interaction $=0.03$ ). However, when waist circumference higher than $88 \mathrm{~cm}$ or body fat percentage (BF \%) measures above the median were used to define obesity, a significant positive relationship was also observed in women with BMI $<30 \mathrm{~kg} / \mathrm{m}^{2}$ but with higher waist circumference or $\mathrm{BF} \%$. In conclusion, our results strengthen the hypothesis that PA has a positive influence on BUA levels, though dependent on weight.

Keywords Bone mineral density - Physical activity . Broadband ultrasound attenuation · Bone loss · Obesity

\section{Introduction}

The prevalence of osteoporosis is increasing worldwide [1]. As a consequence, the incidence of osteoporotic fractures is projected to increase further along with the financial, social, and physical costs of the related treatments [1]. Therefore, a non-pharmacologic primary prevention is highly warranted [1]. Physical activity (PA) is one of the recommended strategies to maximize the peak bone mass in younger years and to minimize age-related bone loss, mostly effective via weight-bearing physical activities [1]. Nevertheless, minimizing falls and fractures risk through strength, flexibility, and balance training is also a central core of this demand [1]. In fact, PA modulates bone remodeling through mechanical stimuli, which results in improvements in mineralization and bone geometry [2].

Broadband ultrasound attenuation (BUA) is a noninvasive, bone health measurement technique at the os calcis without radiation. Previous studies have shown a positive 
association between PA and BUA levels [3-5]. Moreover, a number of studies have also confirmed that BUA is an independent predictor of fractures for both men and women particularly at low BUA values [3, 6, 7].

Besides higher PA levels, also higher body mass index (BMI) has been associated with higher BUA levels [8]. In particular, obesity has been suggested to protect against osteoporosis and several studies have shown a positive association between higher BMI and bone mineral density (BMD) [9-11]. However, inverse relationships between PA and obesity are also known [12]. Yet, how obesity influences the relation between PA and bone mineralization is, so far, unknown. Therefore, we aimed to investigate whether the association between PA and BUA differed according to obesity status.

In the present study, the associations between PA and BUA levels were investigated in a cross-sectional study using data from a large population-based sample of German women. All the analyses were conducted separately by peri-/premenopausal and postmenopausal status additionally considering the obesity status.

\section{Subjects and Methods}

\section{Study Population}

The European Prospective Investigation into Cancer and Nutrition (EPIC) Potsdam Study is part of the multicentre prospective cohort study conducted in 10 European countries, focusing on the relation between nutrition and various chronic diseases. Between 1994 and 1998, 27,548 participants (10,904 men and 16,644 women) aged 35-65 years were randomly selected from the general population of Potsdam and surrounding communities [13]. The recruitment process was based on residentś registration offices, and the study participants were invited by mail to participate in the baseline examination [13]. At baseline, selfadministered questionnaires on nutrition and lifestyle were filled out; computer-based interviews on lifestyle and medical history were conducted and physical examinations performed by trained personnel [13]. From 1996 until the end of the recruitment phase, quantitative ultrasound measurements (QUS) were part of the baseline examination in women. Therefore, from the total female population ( $n=16,644$ ), only 9711 women had QUS measurements. For the present study, we excluded 182 participants due to missing PA values, 117 due to age at baseline below 35 years, 2319 due to uncertain menopausal status, 302 due to surgical menopause, and 4 due to use of glucocorticoids or medication for the treatment of osteoporosis, respectively, both known to affect bone metabolism [14, 15]. Moreover, four peri-/premenopausal women with HRT intake and seven postmenopausal women taking oral contraceptives were excluded. The final study population consisted of 6776 women.

\section{Quantitative Ultrasound Measurement}

The quantitative ultrasound measurements (QUS) were performed on the right os calcis using Achilles Plus Ultrasound Densitometer (Lunar Corporation, Madison, WI 53713, USA) by trained and quality-monitored personnel according to manufacturer instructions. Broadband ultrasound attenuation (BUA) was measured in decibel/ megahertz $(\mathrm{dB} / \mathrm{MHz})$, defined as the slope of the signal attenuation versus the frequency curve in the usually measured range of $0.1-1 \mathrm{MHz}$ [16]. In a substudy, 11 women were measured ten times within 3 weeks and a within person variation coefficient of $1.47 \%$ of BUA was observed [17].

\section{Physical Activity Level}

We used calibrated baseline EPIC-Germany PA data as described in Wientzek et al. [18, 19]. Briefly, the PA levels calculation was based on an Improved Physical Activity Index (IPAI) which was computed using information on weekly sports activities over the past 12 months in summer and winter, weekly cycling, weekly hours of watching television, as well as information on the type of occupational physical activity (sedentary, standing, manual, hard) [19]. Its performance was evaluated in a validation sample compared with the Cambridge Index and the Total PA Index. The IPAI is a valid physical activity index, showing higher correlations with accelerometer counts and physical activity energy expenditure than the Cambridge Index and the Total PA Index in EPIC Potsdam [19].

Next, a statistical model estimated from an EPIC subsample ( $n=1339$ ) was built based on a PA questionnaire and objectively measured PA data (acceleration counts). Segmented regression coefficients adjusted for sex, age, and BMI were fitted to baseline PA data in EPIC-Germany [18].

\section{Anthropometry}

Trained and quality-monitored personnel took the anthropometric measurements (weight, height, and waist circumference) with participants wearing only light underwear and no shoes. Body weight was measured with electronic digital scales, accurate to $100 \mathrm{~g}$ (Soehnle, type 7720/23, Murrhardt, Germany) and the height to the nearest $0.1 \mathrm{~cm}$ by using a flexible anthropometer. BMI was calculated as body weight $(\mathrm{kg})$ divided by squared height $\left(\mathrm{m}^{2}\right)$. Obesity was defined according to BMI measures 
based on the World Health Organization cutoff points as follows: BMI (BMI $<30 \mathrm{~kg} / \mathrm{m}^{2} ;$ BMI $\geq 30 \mathrm{~kg} / \mathrm{m}^{2}$ ). The skinfold thickness at biceps, triceps, subscapular, and suprailiac on the right body site was measured with a standard caliper (Lange, Cambridge, MD, USA). Based on these skinfold thicknesses, body density was derived from the regression equations of Durnin and Womersly, which were used to calculate the percentage of body fat according to Siri's formula [17].

\section{Assessment of Dietary Intake, Lifestyle Characteristic, and Other Covariates}

Dietary intake was assessed with a self-administered food frequency questionnaire including questions on frequency and portion size of 148 items consumed during the previous year [20]. Information on educational level, smoking habits, and medical and reproductive history was obtained by PC-assisted face-to-face interviews. Menopausal status was assessed according to self-reported information about menstrual status and history, e.g., natural menopause or surgical menopause. Postmenopausal status is defined as follows: women with $<3$ months menstruation in the last year, without hysterectomy and/or ovariectomy, and only HRT use with 12 consecutive months without menstruation. Women, who have experienced $\geq 3$ months with menstruation in the last year, without hysterectomy and/or ovariectomy, and no use of HRT, were defined as peri-/premenopausal women. Self-reported medication over the past 4 weeks prior to study enrolment was used to identify users of oral contraceptive, hormone replacement therapy (HRT), glucocorticoids, and specific drugs against osteoporosis.

\section{Statistical Analysis}

All analyses were performed separately for peri-/premenopausal $(n=4230)$ and postmenopausal $(n=2546)$ women. Normally distributed variables (BUA, age, BMI) were reported as mean and standard derivation. Right skewed variables (intake of calcium and alcohol) were reported as median and interquartile range, and log transformed for the analyses. Categorical variables were reported as percentage (smoking status, educational level, oral contraceptive, and HRT use). Multivariable linear regression models were used to estimate the relationships between BUA and PA levels, with BUA as continuous dependent variable. Based on a review of the literature, the following variables were identified as potential confounders: age (continuous), BMI (continuous), smoking status (non-smoker, ex-smoker, current smoker), educational level (unskilled or skilled, technical college, university degree), log-transformed alcohol and logtransformed calcium intake, use of oral contraceptive (yes/ no), and HRT (yes/no), respectively, for peri-/premenopausal and postmenopausal women. For a better understanding of the relationship between PA and BUA, menopausal status-specific quartiles of PA were also calculated. Comparisons between each quartile using the lowest (Q1) as reference were tested using the Dunnett's method. Multiplicative interactions between PA and menopausal status as well as PA and BMI (continuous) were tested in the fully adjusted model by including the cross product terms. To explore the data for nonlinear relationships, polynomial terms were included in the regression models. With the aim to evaluate the clinical relevance of the relationship between PA and BUA levels, a different regression model was built. In particular, the beta coefficients of the mean values of all covariates were fixed, and BUA values were predicted for different values of PA. For postmenopausal women, the mean PA value observed in the highest quartile of PA in the premenopausal group was used. The same sensitivity analysis was performed according to obesity status.

Since in the present study, obesity was defined as BMI $\geq 30 \mathrm{~kg} / \mathrm{m}^{2}$, and considering that the effectiveness of BMI to discriminate fat from lean mass is inadequate [21], we performed additional analyses using body fat percentage (BF \%) and waist circumference measures to define obesity (normal: waist $\leq 88 \mathrm{~cm}$; raised: waist $>88 \mathrm{~cm}$ ). However, as so far no threshold of BF \% for defining obese and nonobese has been set [22], these groups were determined by baseline BF \% above and below the median (35.5\%).

To further investigate whether the associations between BUA and PA levels were modified according to both BMI and $\mathrm{BF} \%$ and in order to evaluate whether the use of BMI to classify obesity leads to misclassification, analyses were additionally stratified by BMI (BMI $<30 \mathrm{~kg} / \mathrm{m}^{2}$; BMI $\geq 30 \mathrm{~kg} / \mathrm{m}^{2}$ ) and BF \% (above or below the median) or waist circumference $(\leq 88 \mathrm{~cm}$ or $>88 \mathrm{~cm})$ using the models outlined above. Formal tests for interaction were performed between BMI, BF \%, and PA levels by including a three-level interaction: $\mathrm{BMI} \times \mathrm{PA}$ levels, $\mathrm{BF} \% \times \mathrm{PA}$ levels, and $\mathrm{BMI} \times \mathrm{BF} \%$ and $\mathrm{BMI} \times \mathrm{BF} \% \times \mathrm{PA}$ levels interaction terms in the fully adjusted model. The same tests were performed using waist circumference instead of BF \%.

All statistical analyses were performed using SAS software, version 9.4 (SAS institute, Cary, N.C., USA).

\section{Results}

The general characteristics of the 6776 women, stratified by menopausal status, are shown in Table 1. Peri-/premenopausal women were younger, and had higher BUA and PA levels. No differences were observed between oral 
Table 1 Characteristics of the study population according to menopausal status (EPIC-Potsdam study, women, $n=6776$ )

\begin{tabular}{|c|c|c|c|}
\hline & Peri-/premenopausal women $(n=4230)$ & Postmenopausal women $(n=2546)$ & $p$ \\
\hline BUA (dB/MHz) & $112.39 \pm 10.05$ & $106.44 \pm 9.95$ & $<0.0001$ \\
\hline Age (years) & $40.78 \pm 4.37$ & $58.85 \pm 4.12$ & $<0.0001$ \\
\hline BMI $\left(\mathrm{kg} / \mathrm{m}^{2}\right)$ & $24.45 \pm 4.30$ & $27.26 \pm 4.64$ & $<0.0001$ \\
\hline Physical activity (counts/min/day) & $41.10 \pm 4.81$ & $31.68 \pm 5.12$ & $<0.0001$ \\
\hline Waist (cm) & $76.96 \pm 10.67$ & $84.94 \pm 11.37$ & $<0.0001$ \\
\hline Smoking status $(\%)$ & & & $<0.0001$ \\
\hline Non-smoker & $2873(67.9)$ & $2104(82.6)$ & \\
\hline Ex-Smoker & $354(8.4)$ & $145(5.7)$ & \\
\hline Current smoker & $1003(23.7)$ & $297(11.7)$ & \\
\hline Educational level (\%) & & & $<0.0001$ \\
\hline Unskilled or skilled & $1519(35.9)$ & $1275(50.1)$ & \\
\hline Technical College & $1126(26.6)$ & $812(31.9)$ & \\
\hline University degree & $1585(37.5)$ & $459(18.0)$ & \\
\hline Oral contraceptive intake $(\%)$ & $1477(34.9)$ & - & $<0.0001$ \\
\hline Hormone replacement therapy $(\%)$ & - & $568(22.3)$ & $<0.0001$ \\
\hline \multicolumn{4}{|l|}{ Nutrients intake } \\
\hline Calcium intake (g/day) & $0.74(0.59,0.95)$ & $0.71(0.56,0.92)$ & $<0.0001$ \\
\hline Alcohol consumption (g/day) & $5.89(2.23,11.56)$ & $3.93(1.14,9.01)$ & $<0.0001$ \\
\hline Protein intake (g/day) & $65.4(54.6,78.9)$ & $64.5(54.4,77.2)$ & 0.0412 \\
\hline
\end{tabular}

Variables are expressed as percentage, or mean and standard deviation, or median and interquartile range

contraceptive user $(n=2753)$ and non-user $(n=1477)$ (data not shown). The interaction term between PA and menopausal status was statistically significant $(p=0.02)$; therefore, all analyses were stratified by peri-/pre- and postmenopausal status.

PA was linearly related to BUA. The positive association observed between PA and BUA remained after adjustment for age, BMI, smoking status, educational attainment, log-transformed alcohol and calcium intake, and hormone use in both groups. In particular, each unit increase in the PA level was significantly associated with 0.38 and $0.30 \mathrm{~dB} / \mathrm{MHz}$ higher BUA levels, respectively, in peri-/premenopausal and postmenopausal women $(p<0.0001)$. Postmenopausal women had lower PA levels compared to peri-/premenopausal women. Analyses performed according to menopausal statusspecific PA quartiles showed the same linear relationship between PA and BUA levels in peri-/premenopausal and postmenopausal women (Table 2). In both groups, the mean BUA levels in the second, third, and fourth quartiles were significantly different from the mean of the referent quartile (Q1). In peri-/premenopausal women, the mean BUA level in the lowest quartile was $110.67 \mathrm{~dB} / \mathrm{MHz} 95 \% \mathrm{CI}(109.80$, 111.54), and in the fourth quartile, the mean BUA was 113.89 dB/MHz $95 \%$ CI $(113.08,114.69)$ ( $p$ values Dunnett's test $<0.009$ ). Postmenopausal women had values of $109.08 \mathrm{~dB} / \mathrm{MHz} 95 \% \mathrm{CI}(109.96,110.19)$ in the top PA level quartile versus values of $105.46 \mathrm{~dB} / \mathrm{MHz} 95 \% \mathrm{CI}$ (104.31,
106.60) in the bottom PA quartile ( $p$ values Dunnett's test $<0.007$ ). An additional analysis in postmenopausal women showed that increasing the PA level from 31.7 to 46.8 counts/min/day could increase the BUA values from 106.4 to $111.0 \mathrm{~dB} / \mathrm{MHz}$. As shown in Table 3, obesity status modifies the relationship between PA and BUA values ( $p$ for interaction $=0.03$ ). Stratified analyses by obesity status (BMI $<30$ vs. BMI $\geq 30 \mathrm{~kg} / \mathrm{m}^{2}$ ) showed that peri-/ premenopausal obese women had higher BUA (115.44 $\pm 9.71 \mathrm{~dB} / \mathrm{MHz})$ levels compared to non-obese $(112.04 \pm 10.03 \mathrm{~dB} / \mathrm{MHz})$. Also postmenopausal women with $\mathrm{BMI} \geq 30 \mathrm{~kg} / \mathrm{m}^{2}$ had higher BUA levels $(108.45 \pm 10.14 \mathrm{~dB} / \mathrm{MHz})$ than non-obese ones $(105.79 \pm 9.80 \mathrm{~dB} / \mathrm{MHz})$. However, the positive association between PA and BUA only remained in both non-obese peri-/ premenopausal and postmenopausal women (Table 3). A sensitivity analysis in obese women $(\mathrm{BMI} \geq 30)$ showed that only increasing PA to levels much higher than those observed in the highest PA quartile of non-obese women (BMI $<30$ ) would lead to clinical meaningful increase in the BUA levels in both groups (data not shown). Stratified sensitivity analyses by obesity status using four BMI categories (BMI $<25.0 \mathrm{~kg} /$ $\mathrm{m}^{2}, 25.0 \mathrm{~kg} / \mathrm{m}^{2}<\mathrm{BMI}<30.0 \mathrm{~kg} / \mathrm{m}^{2}, 30.0 \mathrm{~kg} / \mathrm{m}^{2}<$ BMI $<$ $35.0 \mathrm{~kg} / \mathrm{m}^{2}$, BMI $\geq 35.0 \mathrm{~kg} / \mathrm{m}^{2}$ ) showed positive associations between PA and BUA levels only in non-obese (BMI $<25.0 \mathrm{~kg} / \mathrm{m}^{2}, \quad 25.0 \mathrm{~kg} / \mathrm{m}^{2}<$ BMI $<30.0 \mathrm{~kg} / \mathrm{m}^{2}$ ) peri-/premenopausal and postmenopausal women. However, 
Table 2 Quartiles of physical activity with adjusted BUA values according to menopausal status
Table 3 Quartiles of physical activity with adjusted BUA values stratified by menopausal status and BMI categories $(\mathrm{BMI}<30, \mathrm{BMI} \geq 30)$

\begin{tabular}{ccclc}
\hline & $n$ & PA (counts/min/day) & BUA $(\mathrm{dB} / \mathrm{MHz})$ & $p$ linear trend \\
\hline \multicolumn{5}{l}{ Peri-/premenopausal women $(n=4230)^{\mathrm{a}}$} \\
Q1 & 1057 & $35.67(33.40,37.19)$ & $110.67 \mathrm{CI}(109.80,111.54)$ & $<0.0001$ \\
Q2 & 1058 & $39.84(39.11,40.65)$ & $112.13 \mathrm{CI}(111.46,112.80)^{*}$ & \\
Q3 & 1058 & $42.95(42.27,43.67)$ & $113.41 \mathrm{CI}(112.71,114.11)^{*}$ & \\
Q4 & 1057 & $46.35(45.30,47.93)$ & $113.89 \mathrm{CI}(113.08,114.69)^{*}$ & \\
\hline \multicolumn{7}{l}{ Postmenopausal women $(n=2546)^{\mathrm{b}}$} & & \\
Q1 & 636 & $25.90(23.70,27.33)$ & $105.46 \mathrm{CI}(104.31,106.60)$ & $<0.0001$ \\
Q2 & 637 & $30.16(29.41,30.98)$ & $107.27 \mathrm{CI}(106.30,108.23)^{*}$ & \\
Q3 & 637 & $33.44(32.63,34.38)$ & $107.94 \mathrm{CI}(106.97,108.91)^{*}$ & \\
Q4 & 636 & $37.60(36.20,39.25)$ & $109.08 \mathrm{CI}(109.96,110.19)^{*}$ & \\
\hline
\end{tabular}

Variables are expressed as adjusted mean and $95 \%$ confidence interval, or median and interquartile range. Adjustment: age, BMI, smoking status, education, alcohol intake log transformed, calcium intake log transformed, oral contraceptive use ${ }^{\mathrm{a}}, \mathrm{HRT}^{\mathrm{b}}$

* Significantly different compared to Q1 (ANOVA with Dunnett adjustment)

\begin{tabular}{ccclc}
\hline & $n$ & PA (counts/min/day) & BUA $(\mathrm{dB} / \mathrm{MHz})^{\mathrm{a}}$ & $p$ linear trend \\
\hline \multicolumn{2}{l}{ Peri-/premenopausal } & women $(n=3795) \mathrm{BMI}<30^{\mathrm{a}}$ & & \\
Q1 & 948 & $37.37(35.72,38.40)$ & $110.04 \mathrm{CI}(109.17,110.91)$ & $<0.0001$ \\
Q2 & 949 & $40.63(39.88,41.40)$ & $111.43 \mathrm{CI}(110.71,112.14)^{*}$ & \\
Q3 & 949 & $43.39(42.73,44.04)$ & $113.22 \mathrm{CI}(112.49,113.95)^{*}$ & \\
Q4 & 949 & $46.61(45.60,48.15)$ & $113.70 \mathrm{CI}(112.86,114.53)^{*}$ & \\
\hline
\end{tabular}

Peri-/premenopausal women $(n=435) \mathrm{BMI} \geq 30^{\mathrm{a}}$

$\begin{array}{llll}\text { Q1 } & 108 & 28.73(26.18,30.03) & 116.72 \mathrm{CI}(114.16,119.29) \\ \text { Q2 } & 109 & 32.33(31.67,33.11) & 115.75 \mathrm{CI}(113.67,117.82) \\ \text { Q3 } & 109 & 34.85(34.28,35.65) & 114.98 \mathrm{CI}(112.83,117.13) \\ \text { Q4 } & 109 & 38.24(37.36,39.50) & 117.05 \mathrm{CI}(114.77,119.33)\end{array}$

Postmenopausal women $(n=1918)$ BMI $<30^{\text {b }}$

Q1 $479 \quad 28.64(27.33,29.70) \quad 104.78 \mathrm{CI}(103.60,105.96)<0.0001$

Q2 $\quad 480 \quad 31.84(31.17,32.57)$

Q3 $\quad 480 \quad 34.67(33.90,35.16)$

105.97 CI (104.90, 107.04)

107.23 CI (106.17, 108.29)*

Q4 $\quad 479 \quad 38.42(37.14,39.92)$

108.45 CI (107.22, 109.68)*

Postmenopausal women $(n=628)$ BMI $\geq 30^{\mathrm{b}}$

Q1 157

Q2 $\quad 157 \quad 25.38(23.74,16.16)$

109.79 CI $(107.30,112.27)$

0.24

Q3 $\quad 157 \quad 28.05(27.23,28.68)$

108.98 CI $(106.82,111.16)$

108.79 CI (106.59, 110.99)

Q4 $\quad 157 \quad 31.56(30.26,32.95)$

$111.77 \mathrm{CI}(109.44,114.11)$

Variables are expressed as adjusted mean and $95 \%$ confidence interval, or median and interquartile range. Adjustment: age, BMI, smoking status, education, alcohol intake log transformed, calcium intake log transformed, oral contraceptive use ${ }^{\mathrm{a}}, \mathrm{HRT}^{\mathrm{b}}$

* Significantly different compared to Q1 (ANOVA with Dunnett adjustment) the number of very obese women was rather small which may have limited the power to detect associations (Supplementary Tables $1 \mathrm{~s}$ and $2 \mathrm{~s})$.

A three-level interaction analysis by including a $\mathrm{BMI} \times \mathrm{BF} \% \times \mathrm{PA}, \quad$ or $\mathrm{BMI} \times$ waist circumference $\times$ PA, interaction term in the fully adjusted model showed a significant interaction $(p<0.0001)$. Stratified analyses by obesity/BF \% status showed positive significant relationships only among non-obese women with $\mathrm{BF} \%$ above or below the median, while no significant associations were found in obese women with BF \% either above or below the median (Table 4). Similar results were 
Table 4 Multiple linear regression model on the association between PA and BUA stratified by body fat percentage/waist, BMI, and menopausal status

\begin{tabular}{|c|c|c|c|c|c|c|c|c|c|c|c|c|}
\hline & \multicolumn{6}{|c|}{ Peri-/premenopausal women } & \multicolumn{6}{|c|}{ Postmenopausal women } \\
\hline & \multicolumn{3}{|c|}{$\mathrm{BMI}<30$} & \multicolumn{3}{|c|}{$\mathrm{BMI} \geq 30$} & \multicolumn{3}{|c|}{$\mathrm{BMI}<30$} & \multicolumn{3}{|c|}{$\mathrm{BMI} \geq 30$} \\
\hline & $n$ & $\beta$-coefficient ${ }^{\mathrm{a}}$ & $p$ & $n$ & $\beta$-coefficient ${ }^{\mathrm{a}}$ & $p$ & $n$ & $\beta$-coefficient ${ }^{\mathrm{b}}$ & $p$ & $n$ & $\beta$-coefficient ${ }^{b}$ & $p$ \\
\hline BF $\%<$ Median & 2389 & 0.43195 & $<0.0001$ & $4 *$ & - & - & 949 & 0.32951 & 0.005 & 15 & 0.71665 & 0.7 \\
\hline BF $\%>$ Median & 1405 & 0.36795 & 0.0005 & 420 & 0.12314 & 0.5 & 969 & 0.34944 & 0.002 & 606 & 0.19205 & 0.2 \\
\hline Waist $\leq 88 \mathrm{~cm}$ & 3605 & 0.40446 & $<0.0001$ & 66 & -0.20801 & 0.7 & 1580 & 0.29201 & 0.001 & 54 & 0.04410 & 0.9 \\
\hline Waist $>88 \mathrm{~cm}$ & 190 & 0.59369 & 0.03 & 369 & 0.12581 & 0.5 & 338 & 0.54542 & 0.002 & 574 & 0.18652 & 0.2 \\
\hline
\end{tabular}

$\mathrm{BF} \%$ missing $n=19 ; \mathrm{BF} \%$ median $=35.5 \%$; Variables are expressed as mean and standard deviation; Adjustment: age, BMI, smoking status, education, alcohol intake log transformed, calcium intake log transformed, oral contraceptive use ${ }^{\mathrm{a}}, \mathrm{HRT}^{\mathrm{b}}$

* Calculation not possible due to a low number of individuals within these strata

observed when waist circumference categories were used instead of BF \% (Table 4).

\section{Discussion}

Calcaneal broadband ultrasound attenuation was studied in relation to PA levels, taking into consideration the obesity status, in peri-/premenopausal and postmenopausal women. In this cross-sectional analysis, we observed a significant positive association between PA levels and BUA in peri-/ pre- and postmenopausal women. To date, only a few studies investigated the relationship between PA and BUA levels in women applying complex PA instruments [23, 24]. In particular, in the present study, we used a complex PA score including comprehensive information on weekly sports, cycling, hours of television watched, and different types of occupational PA. This latter point is particularly important considering that other PA domains, such as activity in the workplace, remain very often unexplored [25]. PA instruments that only focus on leisure time PA may indeed underestimate the true activity level. In fact, for many people, a significant proportion of their lifetime exposure to intensive PA will occur in the workplace [26].

Our findings are generally consistent with observations made by other epidemiological studies among women of different ethnicities, using complex PA assessment tools as well. These studies mainly observed a positive association between PA and BUA levels [4, 23, 24, 27], only Brahm et al. and Brunner et al. noticed no association [28, 29].

In line with other population-based studies, mean BUA values observed in the present study reached $112 \mathrm{~dB} / \mathrm{MHz}$ in premenopausal $[30,31]$ and $106 \mathrm{~dB} / \mathrm{MHz}$ in postmenopausal women $[3,4,29]$. Interestingly, mean BUA levels of $107.2 \mathrm{~dB} / \mathrm{MHz}$ were observed in a group of women that developed a fracture versus BUA levels of $111.2 \mathrm{~dB} / \mathrm{MHz}$ in women who did not [32]. In particular, in this latter prospective study of 422 mainly postmenopausal women, the authors observed a $43 \%$ increased risk of fracture per $1 \mathrm{SD}$ decrease in the BUA levels after a mean follow-up of 2.6 years [32]. The postmenopausal women had lower PA level compared to the peri-/premenopausal women. But interestingly, based on our data, we calculated that in postmenopausal women, an increase of mean PA levels from 31.7 to 46.8 counts $/ \mathrm{min} /$ day, i.e., the mean value observed in the fourth PA quartile of premenopausal women, would induce a change in BUA values from 106.4 $\mathrm{dB} / \mathrm{MHz}$ (values at risk for future fractures) to $111.0 \mathrm{~dB} / \mathrm{MHz}$ (values observed in the non-fracture group of Huopio et al. study). This estimation suggests that increasing the levels of PA might positively influence BUA levels and lower the risk of fractures.

Obesity has been discussed as a protective factor for osteoporotic fractures [33]. However, a meta-analysis based on 25 prospective cohorts, with data of 368,610 women with over 2.2 million person-years of follow-up, observed that high BMI is a risk factor for both humerus and elbow fracture [33]. Moreover, it has been discussed that obese subjects were more likely to fracture their ankle [33]. Though the reason for these site-specific associations is unknown, it has been suggested that it may be related to an increased risk of falling or a greater load upon bones in falls [33].

To our knowledge, this is the first epidemiological study investigating the influence of obesity on the relation between PA and BUA levels. To classify the obesity status we used BMI, the most common anthropometric measure to diagnose obesity, waist circumference, and BF \% measures.

However, to date, the majority of studies have primarily shown associations between BMI only, as a measure of obesity, and BMD. Indeed, a higher BMI has been positively associated with BMD, assessed with dual energy X-ray absorptiometry (DEXA) or BUA [10, 11, 24, 31, 34]. We also observed that obese women had higher BUA levels than non-obese ones. Interestingly, some studies observed both a positive association between weight/BMI and bone mineral density and a negative relationship 
between fat mass and bone mineral density within given weight/BMI categories, measured with DEXA [10, 11, 35, 36]. These results indicate two diverging aspects of obesity and bone health. On the one hand, the positive weightbearing loading related to obesity is a strong mechanical stimulus for improvement of bone mineralization and bone geometry. On the other hand, obesity carries a series of detrimental aspects associated with fat mass [10]. In particular, visceral fat has been associated with increased levels of proinflammatory cytokines, which in turn promote bone resorption and osteoporosis [37]. Therefore, we were particularly interested in investigating the relation between PA and BUA levels taking obesity status into account. Surprisingly, no significant associations were observed between PA and BUA levels in obese peri-/pre- and postmenopausal women, using BMI. To investigate whether these findings were the result of a misclassification bias, likely occurring when BMI is used as a measure of obesity, additional analyses were performed using both $\mathrm{BF} \%$ and established waist circumference cutoff points to further define obesity. However, we detected no significant associations between PA and BUA levels among obese women $\left(\mathrm{BMI} \geq 30 \mathrm{~kg} / \mathrm{m}^{2}\right.$ ) with $\mathrm{BF} \%$ either above or below the median, or waist circumference either above or below the cutoff points. Indeed these results could suggest that weight bearing on the bones, mainly, independently from body fat, lean body mass, muscles or other components, might be related to higher BUA levels. Moreover, the PA levels on average were lower in obese women compared to nonobese. However, we estimated that obese women should increase their PA to very high levels, much higher than those observed in the highest PA quartile of non-obese in both groups, in order to reach a clinical meaningful increase in the BUA levels. Nevertheless, even though in correctly classified obese women based on BMI and waist circumference, or BF \% measurements, we did not observe a significant association between PA and BUA levels, presumably because of habitual loading and possible circulating estrogens [38], PA may still remain a recommendation to maintain bone health. Indeed, low PA levels and high BMI or waist circumference have consistently been shown to be predictors of several comorbidities, including cardiovascular disease [39, 40]. Therefore, women should always be encouraged to stay physically active and adhere to a healthy BMI/waist circumference for long-term health.

This study has some limitations that need to be addressed. First, BUA was derived from QUS measurement on the right os calcis and we did not include measures at other sites or used additional techniques. Despite DEXA is the most frequently used technique for assessing bone mineral density, BUA has been validated several times against this method. [41] Interestingly, in the study of Taal and colleagues, BUA measures performed at the os calcis were highly correlated with femoral neck and total hip DEXA measures [42]. Furthermore, Moayyeri et al. observed a similar performance between BUA and DEXA measures in prediction of long-term fractures risk in the elderly [43]. Overall, these findings suggest that BUA can be used as a valid, inexpensive, easy, and quick alternative assessment tool for bone health, and most importantly, without radiation [1, 44]. The os calcis is a weight-bearing bone [24]. During weight-bearing exercises, when the minimum effective strain at the bone site is exceeded, the strain or deformation at this area becomes an osteogenic stimulus [45]. Based on this, the physical stimulus leads to a shift in trabecular orientation and density of the bone [46]. The force exerted by the ground on a body in contact with it is known as ground reaction force (GRF). GRF with every heel-strike is maximal at the os calcis, so heel might be an appropriate site for evaluation of the effects of PA on bone [24]. Second, the used PA index does not include non-sports activities of daily living. Finally, the current study is limited to Caucasian women, and thus, the results cannot be generalized to men or to other racial/ethnic groups. Finally, this is a cross-sectional study not allowing causal inferences.

Strengths of our study include the population-based sample, the high number of participants, thus ensuring a suitable comparison between peri-/premenopausal and postmenopausal women, and the availability of high quality data as a result of the standardized procedures.

In conclusion, this study shows a positive association between PA and BUA levels in both peri-/premenopausal and postmenopausal women, albeit dependent on obesity status. Though a direct relationship between PA and BUA levels was observed only in non-obese, indeed these findings suggest that women should stay active to increase bone mass in younger years and to maintain bone mass in the elderly.

Acknowledgments The authors thank all study participants of the EPIC-Potsdam Study for their cooperation. Particular thanks are given to the interviewers for their work in data assessment and to the data managers who were faced with this large amount of data, especially Ellen Kohlsdorf.

Conflict of Interest None of the authors have any conflict of interest with any entity with regard to this study.

Human and Animal Rights and Informed Consent All participants gave their written informed consents priori to their inclusion in the study. The study was approved by the Ethical Committee of the Federal State of Brandenburg, Germany, which includes the observance of human rights.

Open Access This article is distributed under the terms of the Creative Commons Attribution 4.0 International License (http://creativecommons.org/licenses/by/4.0/), which permits unrestricted use, distribution, and reproduction in any medium, provided you give 
appropriate credit to the original author(s) and the source, provide a link to the Creative Commons license, and indicate if changes were made.

\section{References}

1. Babatunde OO, Forsyth JJ (2013) Quantitative Ultrasound and bone's response to exercise: a meta analysis. Bone 53:311-318

2. Robling AG, Castillo AB, Turner $\mathrm{CH}$ (2006) Biomechanical and molecular regulation of bone remodeling. Annu Rev Biomed Eng 8:455-498

3. Blanchet C, Giguere Y, Prud'homme D, Turcot-Lemay L, Dumont M, Leduc G, Cote S, Laflamme N, Rousseau F, Dodin S (2003) Leisure physical activity is associated with quantitative ultrasound measurements independently of bone mineral density in postmenopausal women. Calcif Tissue Int 73:339-349

4. Devine A, Dhaliwal SS, Dick IM, Bollerslev J, Prince RL (2004) Physical activity and calcium consumption are important determinants of lower limb bone mass in older women. J Bone Miner Res 19:1634-1639

5. Landin-Wilhelmsen K, Johansson S, Rosengren A, Dotevall A, Lappas G, Bengtsson BA, Wilhelmsen L (2000) Calcaneal ultrasound measurements are determined by age and physical activity. Studies in two Swedish random population samples. J Intern Med 247:269-278

6. McCloskey EV, Kanis JA, Oden A, Harvey NC, Bauer D, Gonzalez-Macias J, Hans D, Kaptoge S, Krieg MA, Kwok T, Marin F, Moayyeri A, Orwoll E, Glusmall io RC, Johansson H (2015) Predictive ability of heel quantitative ultrasound for incident fractures: an individual-level meta-analysis. Osteoporos Int

7. Moayyeri A, Adams JE, Adler RA, Krieg MA, Hans D, Compston J, Lewiecki EM (2012) Quantitative ultrasound of the heel and fracture risk assessment: an updated meta-analysis. Osteoporos Int 23:143-153

8. Welch A, Camus J, Dalzell N, Oakes S, Reeve J, Khaw KT (2004) Broadband ultrasound attenuation (BUA) of the heel bone and its correlates in men and women in the EPIC-Norfolk cohort: a cross-sectional population-based study. Osteoporos Int $15: 217-225$

9. Wee J, Sng BY, Shen L, Lim CT, Singh G, De Das S (2013) The relationship between body mass index and physical activity levels in relation to bone mineral density in premenopausal and postmenopausal women. Arch Osteoporos 8:162

10. Lloyd JT, Alley DE, Hawkes WG, Hochberg MC, Waldstein SR, Orwig DL (2014) Body mass index is positively associated with bone mineral density in US older adults. Arch Osteoporos 9:175

11. Beck TJ, Petit MA, Wu G, LeBoff MS, Cauley JA, Chen Z (2009) Does obesity really make the femur stronger? BMD, geometry, and fracture incidence in the women's health initiativeobservational study. J bone Miner Res 24:1369-1379

12. Pate RR, Taverno Ross SE, Liese AD, Dowda M (2015) Associations among physical activity, diet quality, and weight status in US adults. Med Sci Sports Exerc 47:743-750

13. Boeing H, Korfmann A, Bergmann MM (1999) Recruitment procedures of EPIC-Germany. European Investigation into Cancer and Nutrition. Ann Nutr Metab 43:205-215

14. Seguro LP, Rosario C, Shoenfeld Y (2013) Long-term complications of past glucocorticoid use. Autoimmun Rev 12:629-632

15. Epstein S (2006) Update of current therapeutic options for the treatment of postmenopausal osteoporosis. Clin Ther 28:151-173

16. Langton CM, Palmer SB, Porter RW (1984) The measurement of broadband ultrasonic attenuation in cancellous bone. Eng Med 13:89-91
17. Kroke A, Klipstein-Grobusch K, Bergmann MM, Weber K, Boeing $H$ (2000) Influence of body composition on quantitative ultrasound parameters of the os calcis in a population-based sample of pre- and postmenopausal women. Calcif Tissue Int 66:5-10

18. Wientzek-Fleischmann A (2013) Development and evaluation of a physical activity index using objectively measured physical activity and questionnaire data. Baseline physical activity data calibration and estimation of the associations between physical activity and chronic disease risk in EPIC Germany. Dissertation, Technische Universität Berlin, Berlin

19. Wientzek A, Vigl M, Steindorf K, Bruhmann B, Bergmann MM, Harttig U, Katzke V, Kaaks R, Boeing H (2014) The improved physical activity index for measuring physical activity in EPIC Germany. PLoS One 9:e92005

20. Kroke A, Klipstein-Grobusch K, Voss S, Moseneder J, Thielecke F, Noack R, Boeing H (1999) Validation of a self-administered food-frequency questionnaire administered in the European Prospective Investigation into Cancer and Nutrition (EPIC) Study: comparison of energy, protein, and macronutrient intakes estimated with the doubly labeled water, urinary nitrogen, and repeated 24-h dietary recall methods. Am J Clin Nutr 70:439-447

21. Okorodudu DO, Jumean MF, Montori VM, Romero-Corral A, Somers VK, Erwin PJ, Lopez-Jimenez F (2010) Diagnostic performance of body mass index to identify obesity as defined by body adiposity: a systematic review and meta-analysis. Int J Obes 34:791-799

22. ****Ho-Pham LT, Campbell LV, Nguyen TV (2011) More on body fat cutoff points. Mayo Clinic proceedings 86:584; author reply 584-585

23. Saadi HF, Reed RL, Carter AO, Dunn EV, Qazaq HS, Al-Suhaili AR (2003) Quantitative ultrasound of the calcaneus in Arabian women: relation to anthropometric and lifestyle factors. Maturitas 44:215-223

24. Babaroutsi E, Magkos F, Manios Y, Sidossis LS (2005) Lifestyle factors affecting heel ultrasound in Greek females across different life stages. Osteoporos Int 16:552-561

25. Greendale GA, Huang MH, Wang Y, Finkelstein JS, Danielson ME, Sternfeld B (2003) Sport and home physical activity are independently associated with bone density. Med Sci Sports Exerc 35:506-512

26. Walker-Bone K, D’Angelo S, Syddall HE, Palmer KT, Cooper C, Coggon D, Dennison EM (2014) Exposure to heavy physical occupational activities during working life and bone mineral density at the hip at retirement age. Occup Environ Med 71:329-331

27. Graafmans WC, Bouter LM, Lips P (1998) The influence of physical activity and fractures on ultrasound parameters in elderly people. Osteoporos Int 8:449-454

28. Brahm H, Mallmin H, Michaelsson K, Strom H, Ljunghall S (1998) Relationships between bone mass measurements and lifetime physical activity in a Swedish population. Calcif Tissue Int 62:400-412

29. Brunner C, Pons-Kuhnemann J, Neuhauser-Berthold M (2011) Impact of age, anthropometric data and body composition on calcaneal bone characteristics, as measured by quantitative ultrasound (QUS) in an older German population. Ultrasound Med Biol 37:1984-1992

30. Adami S, Giannini S, Giorgino R, Isaia GC, Maggi S, Sinigaglia L, Filipponi P, Crepaldi G (2004) Effect of age, weight and lifestyle factors on calcaneal quantitative ultrasound in premenopausal women: the ESOPO study. Calcif Tissue Int 74:317-321

31. Yamaguchi J, Truman G, Cameron ID (2000) Lifestyle factors affecting bone ultrasonometry of the calcaneus in Japanese women. Calcif Tissue Int 66:43-46 
32. Huopio J, Kroger H, Honkanen R, Jurvelin J, Saarikoski S, Alhava E (2004) Calcaneal ultrasound predicts early postmenopausal fractures as well as axial BMD. A prospective study of 422 women. Osteoporos Int 15:190-195

33. Johansson H, Kanis JA, Oden A, McCloskey E, Chapurlat RD, Christiansen C, Cummings SR, Diez-Perez A, Eisman JA, Fujiwara S, Gluer CC, Goltzman D, Hans D, Khaw KT, Krieg MA, Kroger H, LaCroix AZ, Lau E, Leslie WD, Mellstrom D, Melton LJ 3rd, O'Neill TW, Pasco JA, Prior JC, Reid DM, Rivadeneira F, van Staa T, Yoshimura N, Zillikens MC (2014) A meta-analysis of the association of fracture risk and body mass index in women. $\mathrm{J}$ bone Miner Res 29:223-233

34. Gerber LM, Bener A, Al-Ali HM, Hammoudeh M, Liu LQ, Verjee M (2015) Bone mineral density in midlife women: the Study of Women's Health in Qatar. Climacteric 18:316-322

35. Zhao LJ, Liu YJ, Liu PY, Hamilton J, Recker RR, Deng HW (2007) Relationship of obesity with osteoporosis. J Clin Endocrinol Metab 92:1640-1646

36. Hsu YH, Venners SA, Terwedow HA, Feng Y, Niu T, Li Z, Laird $\mathrm{N}$, Brain JD, Cummings SR, Bouxsein ML, Rosen CJ, Xu X (2006) Relation of body composition, fat mass, and serum lipids to osteoporotic fractures and bone mineral density in Chinese men and women. Am J Clin Nutr 83:146-154

37. Sheu Y, Cauley JA (2011) The role of bone marrow and visceral fat on bone metabolism. Curr Osteoporos Rep 9:67-75

38. Thomas T, Burguera B, Melton LJ 3rd, Atkinson EJ, O'Fallon WM, Riggs BL, Khosla S (2001) Role of serum leptin, insulin, and estrogen levels as potential mediators of the relationship between fat mass and bone mineral density in men versus women. Bone 29:114-120
39. Mora S, Lee IM, Buring JE, Ridker PM (2006) Association of physical activity and body mass index with novel and traditional cardiovascular biomarkers in women. JAMA 295:1412-1419

40. Loprinzi P, Smit E, Lee H, Crespo C, Andersen R, Blair SN (2014) The "fit but fat" paradigm addressed using accelerometerdetermined physical activity data. N Am J Med Sci 6:295-301

41. Lappa V, Dontas IA, Trovas G, Constantelou E, Galanos A, Lyritis GP (2007) Quantitative ultrasound is better correlated with bone mineral density and biochemical bone markers in elderly women. Clin Rheumatol 26:1067-1073

42. Taal MW, Cassidy MJ, Pearson D, Green D, Masud T (1999) Usefulness of quantitative heel ultrasound compared with dualenergy X-ray absorptiometry in determining bone mineral density in chronic haemodialysis patients. Nephrol Dial Transpl 14:1917-1921

43. Moayyeri A, Kaptoge S, Dalzell N, Bingham S, Luben RN, Wareham NJ, Reeve J, Khaw KT (2009) Is QUS or DXA better for predicting the 10-year absolute risk of fracture? J bone Miner Res 24:1319-1325

44. Myint PK, Clark AB, Kwok CS, Loke YK, Yeong JK, Luben RN, Wareham NJ, Khaw KT (2014) Bone mineral density and incidence of stroke: European prospective investigation into cancernorfolk population-based study, systematic review, and metaanalysis. Stroke 45:373-382

45. Huiskes R, Ruimerman R, van Lenthe GH, Janssen JD (2000) Effects of mechanical forces on maintenance and adaptation of form in trabecular bone. Nature 405:704-706

46. Karlsson MK, Magnusson H, Karlsson C, Seeman E (2001) The duration of exercise as a regulator of bone mass. Bone 28:128-132 